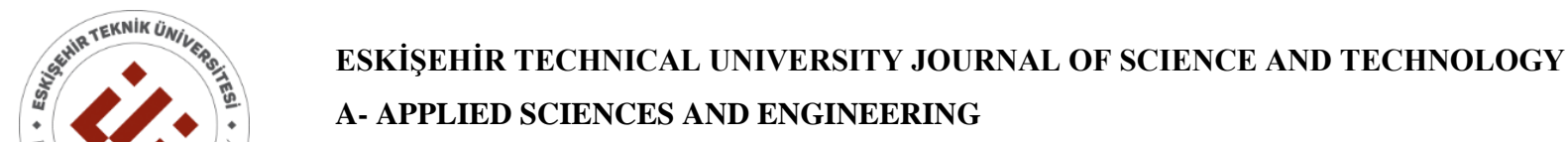

$2020,21(1)$, pp. $58-71$, DOI: $10.18038 /$ estubtda. 562578

\title{
CONFIGURATIONS OF SEVERAL SOFT DECISION-MAKING METHODS TO OPERATE IN FUZZY PARAMETERIZED FUZZY SOFT MATRICES SPACE
}

\author{
Serdar ENGINOĞLU*, Tutku ÖNGEL \\ Department of Mathematics, Faculty of Arts and Sciences, Çanakkale Onsekiz Mart University, Çanakkale, Turkey
}

\begin{abstract}
The concept of fuzzy parameterized fuzzy soft matrices ( $f p f s$-matrices), which allows for processing fuzzy parameters and fuzzy subsets of the alternatives by using computers, is a novel and efficient mathematical tool to cope with uncertainties. Contrary to the methods constructed by $f p f s$-matrices, the known soft decision-making (SDM) methods based on soft sets and fuzzy sets cannot model problems whose parameters and alternatives are fuzzy. Therefore, such methods have been configured to operate in the $f p f s$-matrices space. In this paper, we configure two SDM methods constructed by soft sets, six SDM methods constructed by fuzzy soft sets, two SDM methods constructed by soft matrices, and four SDM methods constructed by fuzzy soft matrices. We then apply the configured methods using one $f p f s$-matrix as input data to a performance-based value assignment problem. Finally, we discuss the need for further research.
\end{abstract}

Keywords: Fuzzy sets, Soft sets, Soft decision-making, Soft matrices, $f p f s$-matrices

\section{INTRODUCTION}

The concept of soft sets proposed by Molodtsov [1] is among popular mathematical tools propounded to model problems involving uncertainties, and so far, many pure and applied studies have been conducted on this concept [2-11]. A soft set is the graphics of a function defined from a set of parameters to the universal set (the set of alternatives). In other words, a soft set is a parameterized family of subsets of the set of alternatives. Here, the sets of parameters and alternatives are two classical sets. Although the concept of soft sets enables modelling some uncertainties, it remains incapable in the event that the parameters or alternatives are fuzzy. To overcome this drawback, several hybrid versions of the soft sets and fuzzy sets [12] have been proposed [13-17]. Among all these versions, fuzzy parameterized fuzzy soft matrices ( $f p f s$-matrices) are the most prominent in terms of performance in the occurrence of decision-making problems in particular [18-26]. Therefore, configuring the soft decision-making (SDM) methods in the literature through $f p f s$-matrices is worth studying.

Lately, Enginoğlu and Memiş [27] have configured some of these methods to operate in $f p f s$-matrices space, faithfully to the original. Thereby, the methods therein have become more competent in modelling the problems in which the parameter set or the images of the parameters are fuzzy. However, when a large number of data come into question, some of these configured methods pose a disadvantage concerning time and complexity. Hence, they have studied to overcome their drawbacks [28-34]. Moreover, the absence of nomenclature of these methods has caused some difficulties. To deal with this problem, they have used the representations consisting of the first letters of the authors' surnames and the last two digits of the publication year. For example, the method in [13] has been denoted by MBR01.

In this paper, we consider the studies in [35-48]. In [35], the authors have examined the application of the weighted fuzzy soft sets in decision-making. [36] has used soft sets in medical diagnosis to diagnose diseases with the soft mapping application. In [37], the authors have availed of the fuzzy soft set to obtain a decision on the worker recruitment problem. In [38], the researchers have decided on investment

*Corresponding Author: serdarenginoglu@gmail.com

Received: 09.05.2019 Published: 31.03.2020 
types via fuzzy soft sets. [39] has studied a multi-evaluation of foreign language teaching using fuzzy soft sets. In [40], the authors attempt to overcome the house purchase problem employing fuzzy soft matrices. [41] has analysed the method of customer satisfaction evaluation using soft sets and its restriction, but the restriction has caused some difficulties [49,50]. Therefore, we have ignored it while configuring the method. The study by [42] has applied fuzzy soft matrices to a company manager's selection problem. In [43], the author has studied the house purchase problem through fuzzy soft sets. [44] features an application on the problem of selecting water purifiers using the fuzzy soft matrices. In [45], the authors have benefited from the fuzzy soft matrices to determine the most eligible candidate. The author in [46] has resorted to soft matrices in the house selection problem. In [47], the authors have applied soft matrices to make the right decision in the fields of health sciences, social sciences, and agriculture. [48] has modelled the problem of buying a laptop by using fuzzy soft sets.

In Section 2 of this study, we present some basic definitions required in the next section of the paper. In Section 3, we configure some of the other SDM methods, faithfully to the original. In Section 4, we apply five of the aforesaid methods to the problem of performance-based value assignment concerning five filters used in image denoising. Finally, we discuss the need for further research. The study was derived from the second author's master's thesis.

\section{PRELIMINARIES}

In this section, firstly, the concept of $f p f s$-matrices $[18,26]$ and some of its basic definitions have been presented. Throughout this paper, let $E$ be a parameter set, $F(E)$ be the set of all fuzzy sets over $E$, and $\mu \in F(E)$. Here, a fuzzy set is denoted by $\left\{{ }^{\mu(x)} x \mid x \in E\right\}$.

Definition 2.1. Let $U$ be a universal set, $\mu \in F(E)$, and $\alpha$ be a function from $\mu$ to $F(U)$. Then, the set $\left\{\left({ }^{\mu(x)} x, \alpha\left({ }^{\mu(x)} x\right)\right): x \in E\right\}$ being the graphic of $\alpha$ is called a fuzzy parameterized fuzzy soft set (fpfs-set) parameterized via $E$ over $U$ (or briefly over $U$ ) $[14,18]$.

In the present paper, the set of all fpfs-sets over $U$ is denoted by $F P F S_{E}(U)$. In $F P F S_{E}(U)$, since the $\operatorname{graph}(\alpha)$ and $\alpha$ generate each other uniquely, the notations are interchangeable. Therefore, as long as it does not cause any confusion, we denote an $f p f s$-set $\operatorname{graph}(\alpha)$ by $\alpha$.

Example 2.1. Let $E=\left\{x_{1}, x_{2}, x_{3}, x_{4}\right\}$ and $U=\left\{u_{1}, u_{2}, u_{3}, u_{4}, u_{5}\right\}$. Then,

$$
\alpha=\left\{\left({ }^{0.8} x_{1},\left\{{ }^{0.3} u_{1},{ }^{0.7} u_{2},{ }^{0.1} u_{4}\right\}\right),\left({ }^{0} x_{2},\left\{{ }^{0.4} u_{2},{ }^{0.9} u_{3}\right\}\right),\left({ }^{0.3} x_{3},\left\{{ }^{0.1} u_{1},{ }^{0.5} u_{3},{ }^{0.4} u_{4}\right\}\right),\left({ }^{0.1} x_{4},\left\{{ }^{0.7} u_{3},{ }^{0.2} u_{5}\right\}\right)\right\}
$$

is an fpfs-set over $U$.

Definition 2.2. Let $\alpha \in F P F S_{E}(U)$. Then, $\left[a_{i j}\right]$ is called the matrix representation of $\alpha$ (or briefly fpfsmatrix of $\alpha$ ) and is defined by

$$
\left[a_{i j}\right]:=\left[\begin{array}{llllll}
a_{01} & a_{02} & a_{03} & \ldots & a_{0 n} & \ldots \\
a_{11} & a_{12} & a_{13} & \ldots & a_{1 n} & \ldots \\
\vdots & \vdots & \vdots & \ddots & \vdots & \vdots \\
a_{m 1} & a_{m 2} & a_{m 3} & \ldots & a_{m n} & \ldots \\
\vdots & \vdots & \vdots & \ddots & \vdots & \ddots
\end{array}\right]
$$

such that for $i \in\{0,1,2, \cdots\}$ and $j \in\{1,2, \cdots\}$,

$$
a_{i j}:= \begin{cases}\mu\left(x_{j}\right), & i=0 \\ \alpha\left({ }^{\mu\left(x_{j}\right)} x_{j}\right)\left(u_{i}\right), & i \neq 0\end{cases}
$$

Here, if $|U|=m-1$ and $|E|=n$, then $\left[a_{i j}\right]$ has order $m \times n[18,26]$.

From now on, the set of all fpfs-matrices parameterized via $E$ over $U$ is denoted by $F P F S_{E}[U]$. 
Example 2.2. The fpfs-matrix of $\alpha$ provided in Example 2.1 is as follows:

$$
\left[a_{i j}\right]=\left[\begin{array}{llll}
0.8 & 0 & 0.3 & 0.1 \\
0.3 & 0 & 0.1 & 0 \\
0.7 & 0.4 & 0 & 0 \\
0 & 0.9 & 0.5 & 0.7 \\
0.1 & 0 & 0.4 & 0 \\
0 & 0 & 0 & 0.2
\end{array}\right]
$$

Definition 2.3. Let $\left[a_{i j}\right]_{m \times n_{1}} \in F P F S_{E_{1}}[U], \quad\left[b_{i k}\right]_{m \times n_{2}} \in F P F S_{E_{2}}[U]$, and $\quad\left[c_{i p}\right]_{m \times n_{1} n_{2}} \in$ $F P F S_{E_{1} \times E_{2}}[U]$ such that $p=n_{2}(j-1)+k$. For all $i$ and $p$,

if $c_{i p}:=\min \left\{a_{i j}, b_{i k}\right\}$, then $\left[c_{i p}\right]$ is called and-product of $\left[a_{i j}\right]$ and $\left[b_{i k}\right]$ and is denoted by $\left[a_{i j}\right] \wedge\left[b_{i k}\right]$, if $c_{i p}:=\max \left\{a_{i j}, b_{i k}\right\}$, then $\left[c_{i p}\right]$ is called or-product of $\left[a_{i j}\right]$ and $\left[b_{i k}\right]$ and is denoted by $\left[a_{i j}\right] \vee\left[b_{i k}\right]$, if $c_{i p}:=\min \left\{a_{i j}, 1-b_{i k}\right\}$, then $\left[c_{i p}\right]$ is called andnot-product of $\left[a_{i j}\right]$ and $\left[b_{i k}\right]$ and is denoted by $\left[a_{i j}\right] \bar{\wedge}\left[b_{i k}\right]$

if $c_{i p}:=\max \left\{a_{i j}, 1-b_{i k}\right\}$, then $\left[c_{i p}\right]$ is called ornot-product of $\left[a_{i j}\right]$ and $\left[b_{i k}\right]$ and is denoted by $\left[a_{i j}\right] \underline{\mathrm{v}}\left[b_{i k}\right][26]$.

Definition 2.4. Let $\left[a_{i j}\right],\left[b_{i j}\right],\left[c_{i j}\right] \in F P F S_{E}[U], I_{E}:=\left\{j: x_{j} \in E\right\}$, and $R \subseteq I_{E}$. If

$$
c_{i j}= \begin{cases}a_{i j}, & j \in R \\ b_{i j}, & j \in I_{E} \backslash R\end{cases}
$$

then $\left[c_{i j}\right]$ is called Rb-restriction of $\left[a_{i j}\right]$ and is denoted by $\left[\left(a_{R b}\right)_{i j}\right]$. Briefly, if $\left[b_{i j}\right]=[0]$, then $\left[\left(a_{R}\right)_{i j}\right]$ can be used instead of $\left[\left(a_{R 0}\right)_{i j}\right][26]$. It is clear that

$$
\left(a_{R}\right)_{i j}=\left\{\begin{array}{cc}
a_{i j}, & j \in R \\
0, & j \in I_{E} \backslash R
\end{array}\right.
$$

Secondly, we give these configured methods MBR01, MRB02, and CCE10 as provided in [27]. Here, MBR01 refers to the method constructed by Maji, Biswas, and Roy in 2001 and MRB02 to the method constructed by Maji, Roy, and Biswas in 2002. Moreover, CCE10 means the method constructed by Çağman, Çıtak, and Enginoğlu in 2010. Throughout this paper, $I_{n}=\{1,2,3, \ldots, n\}$ and $I_{n}^{*}=$ $\{0,1,2,3, \ldots, n\}$.

\section{MBR01 [27]}

Step 1. Construct an $f p f s$-matrix $\left[a_{i j}\right]$

Step 2. Obtain $\left[b_{i k}\right]$ defined by

such that

$$
b_{i k}:=\sum_{j=1}^{n} a_{0 j} \chi\left(a_{i j}, a_{k j}\right), \quad i, k \in I_{m-1}
$$

Step 3. Obtain $\left[c_{i 1}\right]$ defined by

$$
\chi\left(a_{i j}, a_{k j}\right):= \begin{cases}1, & a_{i j} \geq a_{k j} \\ 0, & a_{i j}<a_{k j}\end{cases}
$$

Step 4. Obtain $\left[d_{i 1}\right]$ defined by

$$
c_{i 1}:=\sum_{k=1}^{m-1} b_{i k}, \quad i \in I_{m-1}
$$




$$
d_{i 1}:=\sum_{k=1}^{m-1} b_{k i}, \quad i \in I_{m-1}
$$

Step 5. Obtain the score matrix $\left[s_{i 1}\right]$ defined by

$$
s_{i 1}:=c_{i 1}-d_{i 1}, \quad i \in I_{m-1}
$$

Step 6. Obtain the decision set $\left\{\mu\left(u_{k}\right) u_{k} \mid u_{k} \in U\right\}$ such that $\mu\left(u_{k}\right)=\frac{s_{k 1}+\left|\min _{i} s_{i 1}\right|}{\max _{i} s_{i 1}+\left|\min _{i} s_{i 1}\right|}$

\section{MRB02 [27]}

Step 1. Construct an $f p f s$-matrix $\left[a_{i j}\right]$

Step 2. Obtain the score matrix $\left[s_{i 1}\right]$ defined by

$$
s_{i 1}:=\sum_{j=1}^{n} a_{0 j} a_{i j}, \quad i \in I_{m-1}
$$

Step 3. Obtain the decision set $\left\{\mu\left(u_{k}\right) u_{k} \mid u_{k} \in U\right\}$ such that $\mu\left(u_{k}\right)=\frac{s_{k 1}}{\max _{i} s_{i 1}}$

Note 1. Since the reduction steps in the original algorithm lead to some errors $[49,50]$, these steps have not been considered by the authors in [27].

\section{CCE10 [27]}

Step 1. Construct an $f p f s$-matrix $\left[a_{i j}\right]$

Step 2. Obtain the score matrix $\left[s_{i 1}\right]$ defined by

$$
s_{i 1}:=\frac{1}{\mathrm{n}} \sum_{j=1}^{n} a_{0 j} a_{i j}, \quad i \in I_{m-1}
$$

Step 3. Obtain the decision set $\left\{\mu\left(u_{k}\right) u_{k} \mid u_{k} \in U\right\}$ such that $\mu\left(u_{k}\right)=\frac{s_{k 1}}{\max _{i} s_{i 1}}$

\section{CONFIGURATIONS OF SEVERAL SOFT DECISION-MAKING METHODS}

In this section, we configure some SDM methods constructed by soft sets [36,41], fuzzy soft sets [35,37$39,43,48]$, soft matrices [46,47], and fuzzy soft matrices [40,42,44,45]. The main advantage of the configured methods is that they allow for processing fuzzy parameters and fuzzy subsets of the alternatives by using computers, contrary to the known SDM methods based on soft sets and fuzzy sets. The secondary advantage originates from the fact that it is a novel and efficient mathematical tool to cope with uncertainties, such as a performance-based value assignment problem.

In [35], the authors have examined the application of the weighted fuzzy soft sets in decision-making. We configure the proposed methods therein as follows:

\section{Algorithm 1 (FJLL10)}

Step 1. Construct an $f p f s$-matrix $\left[a_{i j}\right]_{m \times n}$

Step 2. Construct a row matrix $\lambda:=\left[\lambda_{j}\right]_{1 \times n}$ such that $0 \leq \lambda_{j} \leq 1$

Step 3. Obtain $\left[b_{i j}\right]_{m \times n}$ defined by

$$
b_{i j}:= \begin{cases}1, & a_{i j} \geq \lambda_{j} \\ 0, & a_{i j}<\lambda_{j}\end{cases}
$$

such that $i \in I_{m-1}^{*}$ and $j \in I_{n}$

Step 4. Apply MRB02 to $\left[b_{i j}\right]$ 


\section{Algorithm 2 (FJLL10/2)}

Step 1. Construct an $f p f s$-matrix $\left[a_{i j}\right]_{m \times n}$

Step 2. Construct a row matrix $\lambda:=\left[\lambda_{j}\right]_{1 \times n}$ such that $0 \leq \lambda_{j} \leq 1$

Step 3. Obtain $\left[b_{i j}\right]_{m \times n}$ defined by such that $i \in I_{m-1}^{*}$ and $j \in I_{n}$

$$
b_{i j}:=\left\{\begin{array}{cc}
a_{0 j}, & i=0 \\
1, & i \neq 0 \text { and } a_{i j} \geq \lambda_{j} \\
0, & i \neq 0 \text { and } a_{i j}<\lambda_{j}
\end{array}\right.
$$

Step 4. Apply MRB02 to $\left[b_{i j}\right]$

\section{Algorithm 3 (FJLL10/3)}

Step 1. Construct an fpfs-matrix $\left[a_{i j}\right]_{m \times n}$

Step 2. Construct a row matrix $\lambda:=\left[\lambda_{j}\right]_{1 \times n}$ such that $0 \leq \lambda_{j} \leq 1$

Step 3. Obtain $\left[b_{i j}\right]_{m \times n}$ defined by

such that $i \in I_{m-1}^{*}$ and $j \in I_{n}$

$$
b_{i j}:= \begin{cases}1, & a_{i j} \geq \max _{k \in I_{n}} \lambda_{k} \\ 0, & a_{i j}<\max _{k \in I_{n}} \lambda_{k}\end{cases}
$$

Step 4. Apply MRB02 to $\left[b_{i j}\right]$

\section{Algorithm 4 (FJLL10/4)}

Step 1. Construct an $f p f s$-matrix $\left[a_{i j}\right]_{m \times n}$

Step 2. Construct a row matrix $\lambda:=\left[\lambda_{j}\right]_{1 \times n}$ such that $0 \leq \lambda_{j} \leq 1$

Step 3. Obtain $\left[b_{i j}\right]_{m \times n}$ defined by

$$
b_{i j}:=\left\{\begin{array}{cc}
a_{0 j}, & i=0 \\
1, & i \neq 0 \text { and } a_{i j} \geq \max _{k \in I_{n}} \lambda_{k} \\
0, & i \neq 0 \text { and } a_{i j}<\max _{k \in I_{n}} \lambda_{k}
\end{array}\right.
$$

such that $i \in I_{m-1}^{*}$ and $j \in I_{n}$

Step 4. Apply MRB02 to $\left[b_{i j}\right]$

Note 1. If, for all $j, \lambda_{j}=t$, then FJLL10 and FJLL10/2 are denoted by FJLL10t and FJLL10/2t, and are called FJLL10 and FJLL10/2 with the threshold value $t$, respectively. It is clear that FJLL10t and FJLL10/2t are special cases of FJLL10 and FJLL10/2, respectively.

Note 2. If, for all $j, \lambda_{j}=\frac{1}{m-1} \sum_{i=1}^{m-1} a_{i j}$, then $\lambda_{j}$ is called mid-threshold value. Therefore, FJLL10 and FJLL10/2 are denoted by FJLL10m and FJLL10/2m, and are called FJLL10 and FJLL10/2 with the mid-threshold value, respectively. It is clear that FJLL10m and FJLL10/2m are special cases of FJLL10 and FJLL10/2, respectively.

Note 3. If, for all $j, \lambda_{j}=\max _{i \in I_{m-1}} a_{i j}$, then $\lambda_{j}$ is called max-threshold value. Therefore, FJLL10 and FJLL10/2 are denoted by FJLL10max and FJLL10/2max, and are called FJLL10 and FJLL10/2 with the max-threshold value, respectively. It is clear that FJLL10max and FJLL10/2max are special cases of FJLL10 and FJLL10/2, respectively. 
[36] has used soft sets in medical diagnosis to diagnose diseases with the soft mapping application. We configure the proposed method therein as follows:

\section{Algorithm 5 (MS10)}

Step 1. Construct an $f p f s$-matrix $\left[a_{i j}\right]_{m \times n}$

Step 2. Determine $K$ such that $K \subseteq\{1,2, \ldots, n\}$

Step 3. Obtain the score matrix $\left[s_{i 1}\right]$ defined by

$$
s_{i 1}:=\sum_{j \in K} a_{0 j} a_{i j}, \quad i \in I_{m-1}
$$

Step 4. Obtain the decision set $\left\{\mu\left(u_{k}\right) u_{k} \mid u_{k} \in U\right\}$ such that $\mu\left(u_{k}\right)=\frac{s_{k 1}}{\max _{i} s_{i 1}}$

In [37], the authors have availed of the fuzzy soft set to obtain a decision on the worker recruitment problem. We configure the proposed method therein as follows:

\section{Algorithm 6 (CEC11)}

Step 1. Construct an $f p f s$-matrix $\left[a_{i j}\right]_{m \times n}$

Step 2. Obtain $\left[b_{1 j}\right]$ defined by

$$
b_{1 j}:=\frac{a_{0 j}}{m-1} \sum_{i=1}^{m-1} a_{i j}, \quad j \in I_{n}
$$

Step 3. Obtain the score matrix $\left[s_{i 1}\right]_{(m-1) \times 1}:=\frac{1}{n}\left[a_{i j}\right]_{(m-1) \times n}\left[b_{j 1}\right]$ such that $i \in I_{m-1}$ and $j \in I_{n}$

Here, $\left[b_{j 1}\right]$ denotes transpose of $\left[b_{1 j}\right]$.

Step 4. Obtain the decision set $\left\{\mu\left(u_{k}\right) u_{k} \mid u_{k} \in U\right\}$ such that $\mu\left(u_{k}\right)=\frac{s_{k 1}}{\max _{i} s_{i 1}}$

In [38], the researchers have decided on investment types via fuzzy soft sets. We configure the proposed method therein as follows:

\section{Algorithm 7 (KM11)}

Step 1. Construct an $f p f s$-matrix $\left[a_{i j}\right]_{m \times n}$

Step 2. Determine $K$ such that $K \subseteq\{1,2, \ldots, n\}$

Step 3. Obtain the score matrix $\left[s_{i 1}\right]$ defined by

$$
s_{i 1}:=\prod_{j \in K} a_{0 j} a_{i j}, \quad i \in I_{m-1}
$$

Step 4. Obtain the decision set $\left\{\mu\left(u_{k}\right) u_{k} \mid u_{k} \in U\right\}$ such that $\mu\left(u_{k}\right)=\frac{s_{k 1}}{\max _{i} s_{i 1}}$

[39] has studied a multi-evaluation of foreign language teaching using fuzzy soft sets. We configure the proposed method therein as follows:

\section{Algorithm 8 (M11)}

Step 1. Construct an $f p f s$-matrix $\left[a_{i j}\right]_{m \times n}$

Step 2. Obtain $\left[b_{i k}\right]$ defined by

$$
b_{i k}:=\sum_{j=1}^{n} a_{0 j}\left(a_{i j}-a_{k j}\right), \quad i, k \in I_{m-1}
$$


Step 3. Obtain the score matrix $\left[s_{i 1}\right]$ defined by

$$
s_{i 1}:=\sum_{k=1}^{m-1} b_{i k}, \quad i \in I_{m-1}
$$

Step 4. Obtain the decision set $\left\{\mu\left(u_{k}\right) u_{k} \mid u_{k} \in U\right\}$ such that $\mu\left(u_{k}\right)=\frac{s_{k 1}+\left|\min _{i} s_{i 1}\right|}{\max _{i} s_{i 1}+\left|\min _{i} s_{i 1}\right|}$

In [40], the authors attempt to overcome the house purchase problem employing fuzzy soft matrices. We configure the proposed methods therein as follows:

\section{Algorithm 9 (YJ11)}

Step 1. Construct $f p f s$-matrices $\left[a_{i j}^{(1)}\right]_{m \times n},\left[a_{i j}^{(2)}\right]_{m \times n}, \ldots,\left[a_{i j}^{(t)}\right]_{m \times n}$

Step 2. Obtain the score matrix $\left[s_{i 1}\right]$ defined by

$$
s_{i 1}:=\frac{1}{n} \sum_{j=1}^{n} \min _{k}\left\{a_{0 j}^{(k)} a_{i j}^{(k)}\right\}, \quad k \in I_{t} \text { and } i \in I_{m-1}
$$

Step 3. Obtain the decision set $\left\{\mu\left(u_{k}\right) u_{k} \mid u_{k} \in U\right\}$ such that $\mu\left(u_{k}\right)=\frac{s_{k 1}}{\max _{i} s_{i 1}}$

\section{Algorithm 10 (YJ11/2)}

Step 1. Construct $f p f s$-matrices $\left[a_{i j}^{(1)}\right]_{m \times n},\left[a_{i j}^{(2)}\right]_{m \times n}, \ldots,\left[a_{i j}^{(t)}\right]_{m \times n}$

Step 2. Obtain the score matrix $\left[s_{i 1}\right]$ defined by

$$
s_{i 1}:=\frac{1}{n} \sum_{j=1}^{n} \max _{k}\left\{a_{0 j}^{(k)} a_{i j}^{(k)}\right\}, \quad k \in I_{t} \text { and } i \in I_{m-1}
$$

Step 3. Obtain the decision set $\left\{\mu\left(u_{k}\right) u_{k} \mid u_{k} \in U\right\}$ such that $\mu\left(u_{k}\right)=\frac{s_{k 1}}{\max _{i} s_{i 1}}$

[41] has analysed the method of customer satisfaction evaluation using soft sets and its restriction, but the restriction has caused some difficulties [49,50]. Therefore, we have ignored it while configuring the method. We configure the proposed method therein as follows:

\section{Algorithm 11 (WW11)}

Step 1. Construct an fpfs-matrix $\left[a_{i j}\right]_{m \times n}$ such that $\sum_{j} a_{0 j}=1$

Step 2. Apply MRB02 to $\left[a_{i j}\right]$

The study by [42] has applied fuzzy soft matrices to a company manager's selection problem. We configure the proposed method therein as follows:

\section{Algorithm 12 (BNS12)}

Step 1. Construct $f p f s$-matrices $\left[a_{i j}^{(1)}\right]_{m \times n},\left[a_{i j}^{(2)}\right]_{m \times n}, \ldots,\left[a_{i j}^{(t)}\right]_{m \times n}$

Step 2. Obtain the score matrix $\left[s_{i 1}\right]$ defined by

$$
s_{i 1}:=\sum_{j=1}^{n}\left(\prod_{k=1}^{t} a_{0 j}^{(k)} a_{i j}^{(k)}\right), \quad i \in I_{m-1}
$$

Step 3. Obtain the decision set $\left\{\mu\left(u_{k}\right) u_{k} \mid u_{k} \in U\right\}$ such that $\mu\left(u_{k}\right)=\frac{s_{k 1}}{\max _{i} s_{i 1}}$ 
In [43], the author has studied the house purchase problem through fuzzy soft sets. We configure the proposed method therein as follows:

\section{Algorithm 13 (S12)}

Step 1. Construct fpfs-matrices $\left[a_{i j}^{(1)}\right]_{m \times n_{1}},\left[a_{i j}^{(2)}\right]_{m \times n_{2}}, \ldots,\left[a_{i j}^{(t)}\right]_{m \times n_{k}}$

Step 2. Determine an element $\left(j_{1}, j_{2}, \ldots, j_{t}\right) \in\left\{1,2, \ldots, n_{1}\right\} \times\left\{1,2, \ldots, n_{2}\right\} \times \ldots \times\left\{1,2, \ldots, n_{k}\right\}$

Step 3. Obtain the score matrix $\left[s_{i 1}\right]$ defined by

$$
s_{i 1}:=\min \left\{a_{0 j_{1}} a_{i j_{1}}, a_{0 j_{2}} a_{i j_{2}}, \ldots, a_{0 j_{t}} a_{i j_{t}}\right\}, \quad i \in I_{m-1}
$$

Step 4. Obtain the decision set $\left\{\mu\left(u_{k}\right) u_{k} \mid u_{k} \in U\right\}$ such that $\mu\left(u_{k}\right)=\frac{s_{k 1}}{\max _{i} s_{i 1}}$

[44] features an application on the problem of selecting water purifiers using the fuzzy soft matrices. In [45], the authors have benefited from the fuzzy soft matrices to determine the most eligible candidate. We configure the proposed methods therein as follows:

\section{Algorithm 14 (MR13, NB14)}

Step 1. Construct $f p f s$-matrices $\left[a_{i j}^{(1)}\right]_{m \times n},\left[a_{i j}^{(2)}\right]_{m \times n}, \ldots,\left[a_{i j}^{(t)}\right]_{m \times n}$

Step 2. Obtain $\left[b_{i j}\right]_{m \times n}$ defined by

$$
b_{i j}:=\min _{k \in I_{t}} a_{i j}^{(k)}, \quad i \in I_{m-1}^{*} \text { and } j \in I_{n}
$$

Step 3. Apply CCE10 to $\left[b_{i j}\right]$

\section{Algorithm 15 (MR13/2)}

Step 1. Construct $f p f s$-matrices $\left[a_{i j}^{(1)}\right]_{m \times n},\left[a_{i j}^{(2)}\right]_{m \times n}, \ldots,\left[a_{i j}^{(t)}\right]_{m \times n}$

Step 2. Obtain $\left[b_{i j}\right]_{m \times n}$ defined by

$$
b_{i j}:=\prod_{k=1}^{t} a_{i j}^{(k)}, \quad i \in I_{m-1}^{*} \text { and } j \in I_{n}
$$

Step 3. Apply CCE10 to $\left[b_{i j}\right]$

\section{Algorithm 16 (MR13/3)}

Step 1. Construct $f p f s$-matrices $\left[a_{i j}^{(1)}\right]_{m \times n},\left[a_{i j}^{(2)}\right]_{m \times n}, \ldots,\left[a_{i j}^{(t)}\right]_{m \times n}$

Step 2. Obtain $\left[b_{i j}\right]_{m \times n}$ defined by

$$
b_{i j}:=\max \left\{\left(\sum_{k=1}^{t} a_{i j}^{(k)}\right)-t+1,0\right\}, \quad i \in I_{m-1}^{*} \text { and } j \in I_{n}
$$

Step 3. Apply CCE10 to $\left[b_{i j}\right]$

The author in [46] has resorted to soft matrices in the house selection problem. We configure the proposed method therein as follows:

\section{Algorithm 17 (Z14)}

Step 1. Construct two $f p f s$-matrices $\left[a_{i j}\right]_{m \times n}$ and $\left[b_{i j}\right]_{m \times n}$

Step 2. Obtain $\left[c_{i j}\right]_{m \times n}$ defined by $c_{i j}:=\max \left\{a_{i j}, b_{i j}\right\}$ such that $i \in I_{m-1}^{*}$ and $j \in I_{n}$

Step 3. Apply MRB02 to $\left[c_{i j}\right]$ 
In [47], the authors have applied soft matrices to make the right decision in the fields of health sciences, social sciences, and agriculture. We configure the proposed method therein as follows:

\section{Algorithm 18 (ICJ17)}

Step 1. Construct two $f p f s$-matrices $\left[a_{i j}\right]_{m \times n_{1}}$ and $\left[b_{i k}\right]_{m \times n_{2}}$

Step 2. Find and/or/andnot/ornot-product $f p f s$-matrix $\left[c_{i p}\right]$ of $\left[a_{i j}\right]$ and $\left[b_{i k}\right]$

Step 3. Obtain the score matrix $\left[s_{i 1}\right]$ defined by

$$
s_{i 1}:=\min _{k}\left\{\begin{array}{cc}
\max _{p \in I_{k}}\left(c_{0 p} c_{i p}\right), & I_{k} \neq \varnothing \\
0, & I_{k}=\emptyset
\end{array}\right.
$$

such that $i \in I_{m-1}$ and $I_{k}:=\left\{p \mid \exists i, c_{0 p} c_{i p} \neq 0,(k-1) n<p \leq k n\right\}$

Step 4. Obtain the decision set $\left\{\mu\left(u_{k}\right) u_{k} \mid u_{k} \in U\right\}$ such that $\mu\left(u_{k}\right)=\frac{s_{k 1}}{\max _{i} s_{i 1}}$

[48] has modelled the problem of buying a laptop by using fuzzy soft sets. We configure the proposed method therein as follows:

\section{Algorithm 19 (NKY17)}

Step 1. Construct $f p f s$-matrices $\left[a_{i j}^{(1)}\right]_{m \times n},\left[a_{i j}^{(2)}\right]_{m \times n}, \ldots,\left[a_{i j}^{(t)}\right]_{m \times n}$

Step 2. Obtain $\left[b_{i j}\right]_{m \times n}$ defined by

$$
b_{i j}:=\frac{1}{t} \sum_{k=1}^{t} a_{i j}^{(k)}, \quad i \in I_{m-1}^{*} \text { and } j \in I_{n}
$$

Step 3. Obtain $\left[c_{i j}\right]_{m \times n}$ defined by $c_{0 j}:=b_{0 j}$ and $c_{i j}:=\lambda_{i} b_{i j}$ for $i \in I_{m-1}, j \in I_{n}$, and $\sum \lambda_{i}=1$

Step 4. Apply MBR01 to $\left[c_{i j}\right]$

\section{AN APPLICATION TO PERFORMANCE BASED-VALUE ASSIGNMENT PROBLEM OF THE FILTERS USED IN IMAGE DENOISING}

In this section, we apply FJLL10/2, MS10, CEC11, KM11, and M11 to sort five filters used in image denoising by their noise removal performances. Even though it is difficult to sort these filters in the event that the filters perform variously in different noise densities, the SDM methods overcome this difficulty. To illustrate, let us consider mean-SSIM results in Table 1 for 15 traditional images provided in [51].

Table 1. The mean-SSIM results for the 15 traditional images with different SPN ratios

\begin{tabular}{lccccccccc}
\hline \hline Noise Density & $10 \%$ & $20 \%$ & $30 \%$ & $40 \%$ & $50 \%$ & $60 \%$ & $70 \%$ & $80 \%$ & $90 \%$ \\
\hline \hline PSMF & 0.9028 & 0.8715 & 0.8018 & 0.6988 & 0.4903 & 0.1882 & 0.0633 & 0.0318 & 0.0139 \\
DBA & 0.9079 & 0.8664 & 0.8097 & 0.7376 & 0.6521 & 0.5552 & 0.4567 & 0.3623 & 0.2937 \\
MDBUTMF & 0.8841 & 0.7994 & 0.7443 & 0.7657 & 0.7963 & 0.7880 & 0.7501 & 0.6443 & 0.3052 \\
NAFSMF & 0.9147 & 0.8916 & 0.8669 & 0.8409 & 0.8124 & 0.7796 & 0.7403 & 0.6872 & 0.5736 \\
DAMF & $\mathbf{0 . 9 2 5 3}$ & $\mathbf{0 . 9 1 1 3}$ & $\mathbf{0 . 8 9 4 6}$ & $\mathbf{0 . 8 7 5 2}$ & $\mathbf{0 . 8 5 2 3}$ & $\mathbf{0 . 8 2 4 4}$ & $\mathbf{0 . 7 8 9 2}$ & $\mathbf{0 . 7 3 9 8}$ & $\mathbf{0 . 6 5 7 2}$ \\
\hline \hline
\end{tabular}

Assume that the success in high noise densities is more important than in the others. In that case, the values given in Table 1 can be represented with an $f p f s$-matrix as follows: 
Enginoğlu and Öngel / Eskişehir Technical Univ. J. of Sci. and Tech. A-Appl. Sci. and Eng. 21 (1)- 2020

$$
\left[a_{i j}\right]:=\left[\begin{array}{lllllllll}
0.1 & 0.2 & 0.3 & 0.4 & 0.5 & 0.6 & 0.7 & 0.8 & 0.9 \\
0.9028 & 0.8715 & 0.8018 & 0.6988 & 0.4903 & 0.1882 & 0.0633 & 0.0318 & 0.0139 \\
0.9079 & 0.8664 & 0.8097 & 0.7376 & 0.6521 & 0.5552 & 0.4567 & 0.3623 & 0.2937 \\
0.8841 & 0.7994 & 0.7443 & 0.7657 & 0.7963 & 0.7880 & 0.7501 & 0.6443 & 0.3052 \\
0.9147 & 0.8916 & 0.8669 & 0.8409 & 0.8124 & 0.7796 & 0.7403 & 0.6872 & 0.5736 \\
0.9253 & 0.9113 & 0.8946 & 0.8752 & 0.8523 & 0.8244 & 0.7892 & 0.7398 & 0.6572
\end{array}\right]
$$

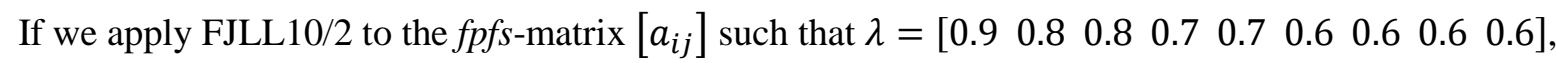
then the score matrix and the decision set are as follows:

$$
\left[s_{i 1}\right]=\left[\begin{array}{lllll}
0.6 & 1 & 3 & 3.6 & 4.5
\end{array}\right]^{T}
$$

and

$$
\left\{{ }^{0.1333} \mathrm{PSMF},{ }^{0.2222} \mathrm{DBA},{ }^{0.6667} \mathrm{MDBUTMF},{ }^{0.8} \mathrm{NAFSMF},{ }^{1} \mathrm{DAMF}\right\}
$$

The scores show that DAMF outperforms the others and the ranking order PSMF $<$ DBA $<$ MDBUTMF $\prec$ NAFSMF $<$ DAMF is valid.

If we apply MS10 to the $f p f s$-matrix $\left[a_{i j}\right]$ such that $K=\{1,2,3,4,5,6,7,8,9\}$, then the score matrix and the decision set are as follows:

$$
\left[s_{i 1}\right]=\left[\begin{array}{lllll}
1.2250 & 2.3351 & 2.9640 & 3.3244 & 3.5498
\end{array}\right]^{T}
$$

and

$$
\left\{{ }^{0.3451} \mathrm{PSMF},{ }^{0.6578} \mathrm{DBA},{ }^{0.8350} \mathrm{MDBUTMF},{ }^{0.9365} \mathrm{NAFSMF},{ }^{1} \mathrm{DAMF}\right\}
$$

The scores show that DAMF outperforms the others and the ranking order PSMF $<$ DBA $<$ MDBUTMF $\prec$ NAFSMF $<$ DAMF is valid.

If we apply CEC11 to the $f p f s$-matrix $\left[a_{i j}\right]$, then the score matrix and the decision set are as follows:

$$
\left[s_{i 1}\right]=\left[\begin{array}{lllll}
0.1151 & 0.1984 & 0.2471 & 0.2728 & 0.2897
\end{array}\right]^{T}
$$

and

$$
\left\{{ }^{0.3972} \mathrm{PSMF},{ }^{0.6847} \mathrm{DBA},{ }^{0.8528} \mathrm{MDBUTMF},{ }^{0.9414} \mathrm{NAFSMF},{ }^{1} \mathrm{DAMF}\right\}
$$

The scores show that DAMF outperforms the others and the ranking order PSMF $<$ DBA $<$ MDBUTMF $<$ NAFSMF $<$ DAMF is valid.

If we apply KM11 to the $f p f s$-matrix $\left[a_{i j}\right]$ such that $K=\{1,2,3,4,5,6,7,8,9\}$, then the score matrix and the decision set are as follows:

$$
\left[s_{i 1}\right]=\left[\begin{array}{lllll}
0.0004 \times 10^{-6} & 2.9994 \times 10^{-6} & 13.5279 \times 10^{-6} & 39.8719 \times 10^{-6} & 64.5911 \times 10^{-6}
\end{array}\right]^{T}
$$

and

$$
\left\{{ }^{0.000006} \mathrm{PSMF},{ }^{0.0464} \mathrm{DBA},{ }^{0.2094} \mathrm{MDBUTMF},{ }^{0.6173} \mathrm{NAFSMF},{ }^{1} \mathrm{DAMF}\right\}
$$

The scores show that DAMF outperforms the others and the ranking order PSMF $<$ DBA $<$ MDBUTMF $<$ NAFSMF $<$ DAMF is valid. 
If we apply M11 to the $f p f s$-matrix $\left[a_{i j}\right]$, then the score matrix and the decision set are as follows:

$$
\left[s_{i 1}\right]=\left[\begin{array}{lllll}
-7.2734 & -1.7230 & 1.4218 & 3.2237 & 4.3508
\end{array}\right]^{T}
$$

and

$$
\left\{{ }^{0} \mathrm{PSMF},{ }^{0.4775} \mathrm{DBA},{ }^{0.7480} \mathrm{MDBUTMF},{ }^{0.9030} \mathrm{NAFSMF},{ }^{1} \mathrm{DAMF}\right\}
$$

The scores show that DAMF outperforms the others and the ranking order PSMF $<$ DBA $<$ MDBUTMF $\prec$ NAFSMF $<$ DAMF is valid.

The fact that the ranking orders by FJLL10/2, MS10, CEC11, KM11, and M11 in Table 2 are the same as the rankings made by an expert opinion without using any methods means that these methods can be applied successfully to the performance based-value assignment problem of the image denoising filters.

\begin{tabular}{|c|c|c|}
\hline Methods & Decision Sets & Ranking Orders \\
\hline FJLL10/2 & $\left\{{ }^{0.1333} \mathrm{PSMF},{ }^{0.2222} \mathrm{DBA},{ }^{0.6667} \mathrm{MDBUTMF},{ }^{0.8} \mathrm{NAFSMF},{ }^{1} \mathrm{DAMF}\right\}$ & PSMF $<$ DBA $<$ MDBUTMF $<$ NAFSMF $<$ DAMF \\
\hline MS10 & $\left\{{ }^{0.3451} \mathrm{PSMF},{ }^{0.6578} \mathrm{DBA},{ }^{0.8350} \mathrm{MDBUTMF},{ }^{0.9365} \mathrm{NAFSMF},{ }^{1} \mathrm{DAMF}\right\}$ & $\mathrm{PSMF}<\mathrm{DBA}<\mathrm{MDBUTMF}<\mathrm{NAFSMF}<\mathrm{DAMF}$ \\
\hline CEC11 & $\left\{{ }^{0.3972} \mathrm{PSMF},{ }^{0.6847} \mathrm{DBA},{ }^{0.8528} \mathrm{MDBUTMF},{ }^{0.9414} \mathrm{NAFSMF},{ }^{1} \mathrm{DAMF}\right\}$ & $\mathrm{PSMF}<\mathrm{DBA}<\mathrm{MDBUTMF}<\mathrm{NAFSMF}<\mathrm{DAMF}$ \\
\hline KM11 & $\left\{{ }^{0.000006} \mathrm{PSMF},{ }^{0.0464} \mathrm{DBA},{ }^{0.2094} \mathrm{MDBUTMF},{ }^{0.6173} \mathrm{NAFSMF},{ }^{1} \mathrm{DAMF}\right\}$ & $\mathrm{PSMF}<\mathrm{DBA}<\mathrm{MDBUTMF}<\mathrm{NAFSMF}<\mathrm{DAMF}$ \\
\hline M11 & $\left\{{ }^{0} \mathrm{PSMF},{ }^{0.4775} \mathrm{DBA},{ }^{0.7480} \mathrm{MDBUTMF},{ }^{0.9030} \mathrm{NAFSMF},{ }^{1} \mathrm{DAMF}\right\}$ & PSMF $<$ DBA $<$ MDBUTMF $<$ NAFSMF $<$ DAMF \\
\hline
\end{tabular}

Table 2. The decision sets and ranking orders of the filters for the state-of-art methods

\section{CONCLUSION}

There are hundreds of SDM methods in the literature. Although a significant part of these methods has been constructed based on soft/fuzzy soft/fuzzy parameterized soft/fuzzy parameterized fuzzy soft sets, the matrix representations of these sets have enabled the methods to be used in a computer. $f p f s$-matrices, one of these matrix representations, have become prominent due to their own natural ability to model uncertainties. To this end, we configured 20 of these methods to operate in $f p f s$-matrices space to be faithful to the original. However, the lack of nomenclature to refer to these methods leads to some difficulties. To cope with this problem, we proposed a notation by using the first letters of the authors' surnames and the last two digits of the publication years. Furthermore, this study serves as a source to configure and simplify other methods for future studies. The occurrence of all these configurations and simplifications is likely to allow for comparing and applying these methods. For more details, see [52-56].

\section{REFERENCES}

[1] Molodtsov D. Soft set theory-first results. Comput Math with Appl 1999; 37(4-5): 19-31.

[2] Maji PK, Biswas R, Roy AR. Soft set theory. Comput Math with Appl 2003; 45(4-5): 555-562.

[3] Maji PK, Roy AR, Biswas R. An application of soft sets in a decision making problem. Comput Math with Appl 2002; 44(8-9): 1077-1083.

[4] Çağman N, Enginoğlu S. Soft set theory and uni-int decision making. Eur J Oper Res 2010; 207(2): 848-855.

[5] Çağman N, Enginoğlu S. Soft matrix theory and its decision making. Comput Math with Appl 2010; 59(10): 3308-3314. 
[6] Razak SA, Mohamad D. A soft set based group decision making method with criteria weight. Int. Scholarly Sci. Res. Innovation 2011; 5(10): 1641-1646.

[7] Enginoğlu S, Çağman N, Karataş S, Aydın T. On soft topology. El-Cezeri J Sci Eng 2015; 2(3): $23-38$

[8] Sezgin A. A new approach to semigroup theory I: Soft union semigroups, ideals and bi-ideals. Algebra Letters 2016; Article ID 3, 46 pages.

[9] Çıtak F, Çağman N. Soft k-int-ideals of semirings and its algebraic structures. Ann Fuzzy Math Informatics 2017; 13(4): 531-538.

[10] Şenel G. The relation between soft topological space and soft ditopological space. Commun Fac Sci Univ Ank Ser A1 Math Stat 2018; 67(2): 209-219.

[11] Karaaslan F. Some properties of AG*-groupoids and AG-bands under SI-product operation. J Intell Fuzzy Syst 2019; 36(1): 231-239.

[12] Zadeh LA. Fuzzy sets. Inf Control 1965; 8(3): 338-353.

[13] Maji PK, Biswas R, Roy AR. Fuzzy soft sets. J Fuzzy Math 2001; 9(3): 589-602.

[14] Çağman N, Çıtak F, Enginoğlu S. Fuzzy parameterized fuzzy soft set theory and its applications. Turkish J Fuzzy Syst 2010; 1(1): 21-35.

[15] Çağman N, Çıtak F, Enginoğlu S. FP-soft set theory and its applications. Ann Fuzzy Math Inform 2011; 2(2): 219-226.

[16] Çağman N, Deli İ. Means of FP-soft sets and their applications. Hacettepe J Math Stat 2012; 41(5): 615-625.

[17] Çağman N, Enginoğlu S. Fuzzy soft matrix theory and its application in decision making. Iran J Fuzzy Syst 2012; 9(1): 109-119.

[18] Enginoğlu S. Soft matrices. PhD Dissertation, Gaziosmanpaşa University, Tokat, Turkey, 2012.

[19] Zorlutuna İ, Atmaca S. Fuzzy parametrized fuzzy soft topology. New Trends Math Sci 2016; 4(1): $142-152$.

[20] Riaz M, Hashmi R. Fuzzy parameterized fuzzy soft topology with applications. Ann Fuzzy Math Inform 2017; 13(5): 593-613.

[21] Riaz M, Hashmi R. Fuzzy parameterized fuzzy soft compact spaces with decision-making, Punjab Univ J Math 2018; 50(2): 131-145.

[22] Riaz M, Hashmi R, Farooq A. Fuzzy parameterized fuzzy soft metric spaces. J Math Anal 2018; 9(2): 25-36.

[23] Razak SA, Mohamad DA. Decision making method using fuzzy soft sets. Malaysian J Fundam Appl Sci 2013; 9(2): 99-104.

[24] Atmaca S, Zorlutuna İ. On topological structures of fuzzy parametrized soft sets. Sci World J 2014, Article ID 164176, 8 pages. 
[25] Deli İ, Çağman N. Relations on FP-soft sets applied to decision making problems. J New Theory 2015; 3: 98-107.

[26] Enginoğlu E, Çağman N. Fuzzy parameterized fuzzy soft matrices and their application in decisionmaking. TWMS J Appl Eng Math; In press.

[27] Enginoğlu S, Memiş S. A configuration of some soft decision-making algorithms via $f p f s-$ matrices. Cumhuriyet Sci J 2018; 39(4): 871-881.

[28] Enginoğlu S, Memiş S. A review on an application of fuzzy soft set in multicriteria decision making problem [P. K. Das, R. Borgohain, International Journal of Computer Applications 38 (2012) 3337]. In: Proceedings of The International Conference on Mathematical Studies and Applications 2018; 4-6 October 2018; Karaman, Turkey. pp. 173-178.

[29] Enginoğlu S, Memiş S. A review on some soft decision-making methods. In: Proceedings of The International Conference on Mathematical Studies and Applications 2018; 4-6 October 2018; Karaman, Turkey. pp. 437-442.

[30] Enginoğlu S, Memiş S. Comment on fuzzy soft sets [The Journal of Fuzzy Mathematics 9(3), 2001, 589-602]. Int J Latest Eng Res Appl 2018; 3(9): 1-9.

[31] Enginoğlu S, Memiş S, Arslan B. A fast and simple soft decision-making algorithm EMA18an. In: Proceedings of The International Conference on Mathematical Studies and Applications 2018; 4-6 October 2018; Karaman, Turkey. pp. 428-436.

[32] Enginoğlu S, Memiş S, Arslan B. Comment (2) on soft set theory and uni-int decision-making [European Journal of Operational Research, (2010) 207, 848-855]. J New Theory 2018; 25: 84-102.

[33] Enginoğlu S, Memiş S, Öngel T. A fast and simple soft decision-making algorithm EMO18o. In: Proceedings of The International Conference on Mathematical Studies and Applications 2018; 4-6 October 2018; Karaman, Turkey. pp. 179-187.

[34] Enginoğlu S, Memiş S, Öngel T. Comment on soft set theory and uni-int decision-making [European Journal of Operational Research, (2010) 207, 848-855]. J New Results Sci 2018; 7(3): 28-43.

[35] Feng F, Jun YB, Liu X, Li L. An adjustable approach to fuzzy soft set based decision making. J Comp Appl Math 2010; 234: 10-20.

[36] Majumdar P, Samanta SK. On soft mappings. Comput Math with Appl 2010; 60: 2666-2672.

[37] Çağman N, Enginoğlu S, Çıtak F. Fuzzy soft set theory and its applications. Iran J Fuzzy Syst 2011; 8(3): 137-147.

[38] Kalaichelvi A, Malini PH. Application of fuzzy soft sets to investment decision making problem. Int J Math Sci Appl 2011; 1(3): 1583-1586.

[39] Mou Z. Dynamic multi-evaluation of college foreign language teaching based on fuzzy soft set. Energy Proc 2011; 13: 3183-3188.

[40] Yang Y, Ji C. Fuzzy soft matrices and their applications. In: Deng H., Miao D., Lei J., Wang F.L. (eds) Artificial Intelligence and Computational Intelligence. AICI 2011. Lecture Notes in Computer Science, vol 7002. Springer, Berlin, Heidelberg, pp. 618-627. 
[41] Wu J, Wang Y. A 3PL enterprise customer satisfaction evaluation method based on soft sets. In: IEEE 2011 Seventh International Conference on Natural Computation; pp. 1885-1888.

[42] Borah MJ, Neog TJ, Sut DK. Fuzzy soft matrix theory and its decision making. Int J Mod Eng Res 2012; 2(2): 121-127.

[43] Sut DK. An application of fuzzy soft relation in decision making problems. Int J Math Trends and Tech 2012; 3(2): 50-53.

[44] Mondal JI, Roy TK. Theory of fuzzy soft matrix and its multi criteria in decision making based on three basic t-norm operators. Int J Innovative Res Sci, Eng Tech 2013; 2(10): 5715-5723.

[45] Nagarajan R, Balamurugan K. Decision making approach for solving fuzzy soft matrix. J Shree Velagapudi Ramakrishna Memorial Coll 2014; 2(3): 23-33.

[46] Zhang Z. A new method for decision making based on soft matrix theory. J Sci Res Rep 2014; 3(15): 2110-2117.

[47] Inthumathi V, Chitra V, Jayasree S. The role of operators on soft set in decision making problems. Int J Comput Appl Math 2017; 12(3): 899-910.

[48] Nagarani S, Kalyani S, Yookesh TL. A soft set approach for selecting the best laptop under fuzzy environment. Int J Comput Math Sci 2017; 6(2): 1-4.

[49] Chen D, Tsang ECC, Yeung DS, Wang X. The parameterization reduction of soft sets and its applications. Comput Math with Appl 2005; 49: 757-763.

[50] Kong Z, Gao L, Wang L, Li S. The normal parameter reduction of soft sets and its algorithm. Comput Math with Appl 2008; 56: 3029-3037.

[51] Erkan U, Gökrem L, Enginoğlu S. Different applied median filter in salt and pepper noise. Comput Electr Eng 2018; 70: 789-798.

[52] Enginoğlu S, Ay M, Çağman N, Tolun V. Classification of the monolithic columns produced in Troad and Mysia Region ancient granite quarries in Northwestern Anatolia via soft decisionmaking. Bilge Int J Sci and Tech Res 2019; 3, 21-34.

[53] Enginoğlu S, Memiş S, Çağman N. A generalisation of fuzzy soft max-min decision-making method and its application to a performance-based value assignment in image denoising. El-Cezerî J Sci Eng 2019; 6(3), 466-481.

[54] Enginoğlu S, Memiş S, Karaaslan F. A new approach to group decision-making method based on TOPSIS under fuzzy soft environment. J New Results Sci 2019; 8(2), 42-52.

[55] Memiş S, Enginoğlu S. An application of fuzzy parameterized fuzzy soft matrices in data classification, In: Proceedings of ICONST NST 2019 International Conferences on Science and Technology Natural Science and Technology, 26-30 August 2019, Prizren, Kosovo, pp 68-77.

[56] Memiş S, Enginoğlu S, Erkan U. A data classification method in machine learning based on normalised hamming pseudo-similarity of fuzzy parameterized fuzzy soft matrices. Bilge Int J Sci and Tech Res 2019; 3, 1-8. 